\title{
The Impact of Productivity in the Insurance Cycle
}

\author{
by A. R. N. Ratcliff *
}

In the 1970's insurers in most European countries were protected by tariff bases designed, so it would seem, to ensure that the least efficient operator did not make a loss and where productivity was the key to maximising profitability.

It was clear to many in the industry that consumerist pressures would lead, one way or another, to the break up of these artificial premium structures and the view was held that premiums would be driven down to the level at which supply and demand would be in balance with the more efficient supplying the market and the least efficient being driven out. The argument thus ran that when our traditional protections would break down, whether under the impact of consumerism or because of internal tensions, productivity would be the key factor in our competition for business.

If we regard our premiums as built up of three elements - the pure cost of the risk, the expense cost and the profit margin, this argument must be based on the inherent assumption that the pure cost of the risk can be identified and that Underwriter $A$ will arrive at the same cost as Underwriter $B$ and, if we have regard to investment earnings, that the pure cost of the risk is arrived at by discounting the cost of claims for the expected period between payment of the premium and settlement.

Even on these assumptions, therefore, we can identify a further competitive factor in addition to the expense cost and that is the ability to maximise investment earnings. The definition of investment earnings is a matter of some complexity - and indeed controversy - to which I return below but, more important still, is the assessment of the cost of claims which in practice, as opposed to theory, can be subject to considerable variation as between different underwriters - not least because the claims " experience " which they will be observing is (depending on the class of business) largely made up, at any interval of time, of estimates of outstanding claims, including claims incurred but not reported.

In the Seventies the prevailing productivity conditions led to a drive by non-life insurance companies to reduce their operating costs. This drive sprung in part from a realisation that to be providing less than $£ 70$ worth of service for every $£ 100$ worth of premiums, laid us open to public criticism, a criticism not helped in the UK by our

* Chief General Manager, Eagle Star Insurance Company Limited, London. 
practice of including costs of surveying and of claims service in our overall administrative expenses. Once this criticism was established, it became a factor in competition at a time when the basic cost of the risk was not seriously under attack.

Even if rating structures are designed to impose a heavier expense loading on the small or personal buyer and a lighter loading on the large buyer, this still leaves, in the latter case, a substantial gap between the premium paid and the expected return. This factor and the added cash flow attractions to Finance Directors in industry and commerce during a period of financial stringency and high interest rates led to a marked expansion in the scale of operations of captive insurers world-wide. On top of this, economic recession has resulted in a reduction in the amount of business available to insurers and the significant loss of premium (in real terms) has led to a world-wide surplus of insurance capacity which in turn has enabled the captives to obtain excess reinsurance on such favourable terms that this has given another twist to the screw.

For the direct insurer the attraction of maximising investment income by so-called " cash flow" underwriting has inevitably worn off as the cost of claims has caught up with reduced premium rates but at the same time investment values have increased producing unrealised capital appreciation in the assets matching the technical liabilities. In these circumstances insurers who have already written off insurance losses against investment income are now tempted by the theory that part, if not all, of the unrealised capital appreciation can be regarded as secure against any future fall in investment values and used to justify a situation in which insurance losses are exceeding investment income.

A slightly less obvious manifestation of the same heresy is the assumption that growth in the value of the insurer's capital base or solvency margin arising from fortuitous increases in investment values (often indeed induced by falling interest rates) enables the insurer to expose his portfolio to a greater degree of risk. The heresy creeps in when this in turn is translated into more "imaginative" (i.e. competitive) underwriting converting the risk of loss into a certainty of loss.

To a greater or lesser degree these features have been present in non-life insurance markets world-wide. The net effect for the UK, viewed in real terms, is that administrative and claims costs have been borne by a shrinking premium income. In the 80 's a number of us are now having to operate in markets where the traditional tariff protections have disappeared and the theory that productivity would determine competition for business clearly does not hold water. We do not compete on expensive ratios, we do not compete on maximisation of investment earnings, we do not even compete on risk selection and measurement. We compete for business on premiums and the underwriter who quotes the lowest premium is the one who gets the business.

Whilst in the seventies few disagreed with the view that in the next decade competition would be determined by productivity and that productivity was measured by expense ratios, now that the 80's have arrived this view is seen to be an oversimplification.

Conventionally we have simply regarded productivity as a measure of our operating costs in relation to premium income and this index can therefore be reduced (and hence "productivity" improved) either by a decrease in the operating costs or by an increase in the premium volume (as was by and large the case in the 1970's). 
Thus measured, an improvement in "productivity" by no means necessarily indicated an increase in profitability. If for example the marginal costs of production tip the balance between premiums and claims into loss, then each additional unit sold at the margin increases this loss. That is of course the case where the premium net of commission is less than expected claims discounted by interest.

In this situation a decrease in so-called productivity, resulting from a reduction in premium volume at the margin, will increase our profit and, even if our marginal costs are zero - the ultimate in productivity - we will maximise our profits by cutting down our business - that is by cutting out unprofitable business - business where claims exceed premiums net of commission plus the investment income expected to be earned thereon, and not forgetting that in many branches - motor and liability for example - inflation of claims costs will offset investment earnings.

The statement of the obvious, so laboriously arrived at, may seem an insult to the intelligence of the reader, but in the major insurance markets of the world the over-simplified view of productivity held in the 1970's has led, and is still leading, major companies to underwrite business for premium volume at rates of premium which will inevitably produce losses.

The conclusion is of course that all our decisions, but particularly our underwriting decisions, should be determined by the expectation of profit even if only in terms of marginal costing. Every unit of our organisations where such decisions are taken should be regarded as a profit centre and judged accordingly and this predicates an effective system of internal cost accounting. Premium targets can, and in present circumstances are likely to, militate against profit consciousness. Any conflict between Underwriting Managers and Development Managers must be identified and firmly resolved in favour of the underwriters.

To examine the real impact of productivity we should first consider the characteristics of the markets in which we operate.

The needs and preferences of our customers generally dictate that we provide a localised service - even in the case of multi-national firms. The idea, even within the European Community, that Freedom of Services will create a situation in which national frontiers will no longer define the practical area of operation for an insurer but will be replaced by the Community frontier is far away.

For the 80's the overwhelming tendency will prevail for those of us who operate outside our own frontiers to do so through local subsidiary companies or autonomous branches issuing policies in the language and currency, and subject to the local law of the country concerned. For all practical purposes we can regard these as independent markets.

To illustrate my points $I$ have taken figures drawn from the UK insurance industry but $I$ have no reason to believe that the picture elsewhere is significantly different.

During the 1970's insurance companies achieved a steady reduction in their expense ratios reaching a low point in 1979. Since then, however, operating expenses have increased at a greater rate than premium income and the following figures illustrate crudely the situation in the market in the years 1979-1981. 
INSURANCE IN U.K.

(amounts in $f$ million approx.)

1979

9,600

1,700

17.7
1980

11,400

2,100

18.4
1981

13,400

2,500

18.7

(3) As Percentage of (1)

In each of these years the technical trading loss in respect of non-life business amounted to approx. $£ 100 \mathrm{~m}$ whilst profits from life assurance business transferred to their shareholders varied around $f 140 \mathrm{~m}$.

However, investment income earned on non-life technical reserves in respect of UK and overseas business amounted to $£ 980 \mathrm{~m}$ in 1979 , rising to $£ 1,400 \mathrm{~m}$ in 1981 , a rate of increase marginally greater than the rate of increase in premiums.

I have no doubt that in 1982 our expense ratios have increased further, notwithstanding the slowing down in the rate of inflation, and this is likely to characterise conditions in the 1980's until there is a resurgence of economic activity.

In the past, insurance companies have tended to attack their expense ratio by increasing the premium throughput rather than by reducing costs. In the 1980's however our expectations for further growth of business in real terms can only be minimal and the combined pressure of market overcapacity and more efficient technology will surely force our industry into a smaller number of large units. The more efficient use of resources resulting from such mergers is likely to be a major factor in holding back the continuing trend to higher expense ratios.

Whilst collectively, insurance companies could exercise an influence over market forces, there are few companies in a position to do so on ther own unless they are in a monopoly situation or have the benefit of state support (or quasi monopoly support e.g. from the banking system). Apart from the control we must exercise on our individual selection of risks, that is control of premium ratings and underwriting, the one factor we can influence is our own productivity. We should no longer think of productivity in terms of expense ratio, that is of maximising the premium in relation to cost of the resources employed in each sector of our business, but should look to cut the actual amounts of expenditure on such resoures.

The resources we employ are machinery, communications, paper and people (and people related adjuncts such as offices, cars, etc.).

In very general terms, the main categories of operating expense incurred by UK insurance companies - whether life or general - can be illustrated as follows :

Salaries

Social Security \& Fringe Benefits

Motor Cars and Travel

Property Costs
50 per cent of total

25 per cent of total

4 per cent of total

10 per cent of total 
Making a total of nearly 90 per cent for expenses that are directly related to the number of people we employ - even if property costs are somewhat inelastic.

The balance of just over 10 per cent can be regarded as directly related to the volume of business we transact, although computer costs again are somewhat inelastic.
Post, telephone and stationery
5 per cent of total
Computer Operations (excluding staff)
3 per cent of total
Miscellaneous expenses
3 per cent of total

Whilst recognising the good housekeeping aspects of controlling all items of expenditure by budgetary techniques, it is clear from this that any determined attack on operating costs must be concerned with the problem of controlling staff numbers and levels of salary.

Different insurance markets are at different stages of development but the patterns seem similar. In particular, in most markets it seems to be recognised that insurance companies have been overstaffed in the past and there has been considerable scope for staff reductions.

Above all we need to achieve a significant shift in the balance between the numbers actually producing business or directly servicing our agents and customers and those engaged in office functions. The widespread impact of advanced technology on industry and commerce increases the degree of expertise required of an insurer's sales, service and claims staffs as for example identified in the Geneva Association Study on Computer Risks. Where domestic business or " personal lines" are concerned consumerism and similar forces are requiring an increased "personalisation" of our activity.

For example, the consumer is encouraged by the media to complain in an effective manner if his expectations are not met and our public image depends far more on dealing with such complaints intelligently than on any high-powered P.R. advertising campaign. Certainly $I$ regard the monitoring of individual customer complaints as an important aspect of any General Manager's job.

The management tools for controlling staff costs must be the establishment of manpower budgets based on recognised staffing levels in every unit of operation and these must be determined having regard to planned business achievement and the current state of automation rather than any historical preconceptions of staff numbers. To achieve this requires both work measurement and quality control on the one hand the regular independent systems audits on the other. We must however be on our guard against control systems which themselves absorb significant amounts of manpower and paper for their operation as these may be counter-productive, not only in terms of cost saving, but, more importantly, in terms of motivation. As such techniques are improved, however, they will further impact on the staffing levels required and provide the basis for a further restructuring of job functions.

The extent to which surplus staff can be easily shed varies from country to country but evaluation and recognition of the extent of the problem will certainly assist even in countries with the most protective labour laws or trade union practices.

In extreme cases employers will be under pressure to absorb the surplus by concealed unemployment, job sharing, drastic reduction of working hours. All these can 
only lead to increased inefficiency - which it may be difficult to eradicate at a later date when the immediate problem has disappeared. In any event the social problems raised by unemployment are matters to be tackled by the State, not by the insurance industry on its own.

Most insurance companies entered the 1980's with powerful main frame computer installations, possibly fed data from distant terminals using Visual Display Units. The computational demands on these systems were relatively simple and their main function was the production of the tons of printed paper which our traditional systems demand : Insurance policies, renewal invitations, accounting documents and agents accounts, as well as masses of so-called management statistics.

In certain areas it has been possible to cut through this paper printing output for example by supplying agents with computer tapes for processing on their own computers instead of printed statements of account. In the field of group insurance business, provision of a terminal in a customer's office can enable him to interrogate his own data held on the main frame computer cutting out paper or telephone enquiries and responses. However, if the future does hold in store radical changes along these lines I can not see them being realised in the 1980's and for the time being the main frame computer, possibly assisted by satellites, will continue to print paper on the present scale. In fact we need to exercise rigorous discipline over the use of our greater computer power to produce more or less desirable further management information involving not only more extensive, and less efficient, use of the data base but also requiring inflation of the material on the file with a consequent increase in the data to be captured, amendments to be processed and possibilities for error.

Technological change will have its greatest impact during the 1980's in the field of communications. Distributed network exchanges which can handle both voice and ultra high-speed data transmission will have a major impact on our structure enabling us further to decentralise decision-making. The cost effectiveness of the technological changes will indeed stem as much from the benefits we can secure from structural change as from the technology itself. By cutting out intermediate reporting strata from the structural pyramid - and the multiplication of operations presently taking place - we can reduce its height relative to the pyramid base and thus benefit from shortened and more flexible lines of comunication.

This less hierarchical and more flexible structure will in turn strengthen the process of decentralised decision making but it will impact most directly on the strata of middle management. The restructuring will require to be carefully controlled to avoid demoralisation and consequent anti-selection. Where salaries are determined by collective negotiation, this should lead to a widening of salary ranges - by no means in an upward direction; at present, in many cases, collective negotiation has resulted in the salaries of the good, the bad and the indifferent being too closely associated.

It is of paramount importance to obtain the understanding and commitment of management at all levels before embarking on such restructuring in order to be satisfied that management skills and attitudes are attuned to cope with both the technological and the structural change. Any uncertainty managers feel about their own situation must react against achieving this commitment. 
A major opportunity which can arise is the reorientation of staff at branch locations from clerical functions to sales and claims support functions and indeed to sales activity, thus achieving the shift in the balance between numbers actually engaged in servicing activity and those working on office functions.

Commitment to technological and structural change predicates an informed acceptance not only by managers but also by staff of changes affecting their own operations, and projects must be broken down into components capable of early assimilation and manageable programming rather than "grand designs" which take years to achieve. In turn this needs effective communication between managers down the line and the EDP department.

To achieve all this within a cooperative, as opposed to a confrontational, staff relations environment will require great attention on the part of general management to consultation with representatives of the work force and to the widest communication of plans and objectives. Equally, however, management can not afford to compromise on the plans and objectives once they have been decided.

The adoption of a firm line predicates a recognition of any vulnerability to lack of cooperation and of an emergency system which can operate if cooperative working of systems is withdrawn, and few companies go this far in their planning. In the insurance industry the companies which survive the 1980's will be fewer and leaner than the companies in the market today. The means are at hand to achieve this but only those who react in awareness and in advance of the situation will survive. 